\title{
Endoxa, hypólepsis parádoxos y martyría en la teoría de la esclavitud de Aristóteles
}

Recibido: 17/08/2019 | Revisado: 13/12/2019 | Aceptado: 09/01/2020

DOI: 10.17230/co-herencia.17.32.9

\author{
Luz Gloria Cárdenas* \\ luzgloria4@hotmail.com
}

\begin{abstract}
Resumen En este artículo me ocupo inicialmente de la teoría de la esclavitud de Aristóteles en el libro i de la Política, con el fin de mostrar la utilización de dos procedimientos: uno dialéctico, a partir de la discusión con Platón, y otro retórico, con la utilización de metáforas y testimonios con los que configura el marco epistemológico de su teoría. Luego, me concentraré en un asunto por esclarecer: la diferencia ente los endoxa, la tesis (hypólepsis parádoxos) y el testimonio (martyría). Al describir el método dialéctico en los Tópicos, Aristóteles precisa el significado de los términos endoxa y tesis. Por su parte, en los libros I y II de la Retórica, Aristóteles se ocupa del testimonio. Por consiguiente, identificaré estos dos tipos de procedimientos, los tipos de pruebas y las conclusiones en el libro i de la Política de Aristóteles, a partir de las características elaboradas en los Tópicos y en la Retórica.
\end{abstract}

\section{Palabras clave:}

Aristóteles, endoxa, testimonio, tesis, retórica, dialéctica, esclavitud.

\section{Endoxa, Hypólepsis Parádoxos and Martyría in Aristotle's Theory of Slavery}

Abstract This paper initially discusses Aristotle's theory of slavery in his Book I of Politics in an attempt to demonstrate the use of two procedures: a dialectic process, based on his discussion with Plato, and a rhetorical process, using metaphors and testimonies to set up an epistemological framework for his theory. Subsequently, this work focuses on an issue to be elucidated: the difference between endoxa, thesis (hypólepsis parádoxos), and testimony (martyria). In his description of the dialectical method in Topics, Aristotle explicitly states the meaning of "endoxa" and "thesis". Furthermore, he discusses the term "testimony" in Books I and II of Rhetoric. Consequently, these two types of procedures,
Doctora en Filosofía de la Universidad de Antioquia. Profesora de cátedra de la Universidad del Cauca, Popayán, Colombia. ORCID: 0000-00024541-6152 
the types of proof, and the conclusions in his Book I of Politics will be identified based on the characteristics described in Topics and Rhetoric.

\section{Keywords:}

Aristotle, endoxa, testimony, thesis, rhetoric, dialectic, slavery.

Esta indagación se inscribe en los estudios que se han realizado hasta el momento sobre el papel de la dialéctica y la retórica en las investigaciones de Aristóteles. Según Aubenque (1984), Hegel fue el primero en advertir que Aristóteles procedía dialécticamente en la construcción de su pensamiento filosófico. ${ }^{1}$ Después, en el siglo XX se dio inicio a una serie de investigaciones sobre este tema, entre ellas la Logique et méthode chez Aristote de Le Blond (1939), que llevaron a la realización de un coloquio en 1960 en el que varios comentaristas se ocuparon de presentar las formas en que Aristóteles procedía dialécticamente en varias de sus obras. ${ }^{2}$

Posteriormente, otras precisiones fueron realizadas, verbigracia, por Nussbaum (1995) y Berti (2001-2002; 2009). Paralelamente, desde las nuevas investigaciones sobre la retórica, ${ }^{3}$ los comentaristas han llamado la atención sobre el uso que hace Aristóteles de ciertos recursos retóricos en la construcción de su pensamiento filosófico. Es el caso de Eutimio Martino (1975) y Alfredo Marcos (1996), quienes identifican los usos que hace de la analogía y de la metáfora. Martino se enfoca en el estudio de Acerca del alma; Marcos, en contraste, se ocupa de los tratados biológicos.

1 "Hegel parece haber sido el primero -en sus Lecciones sobre la historia de la filosofía- en observar esa desproporción entre la teoría aristotélica de la ciencia, en los Analíticos y su especulación efectiva en la Metafísica" (Aubenque, 1984, p. 240).

2 Ver: Symposium Aristotelicum (1980).

3 En el siglo xx se renuevan los estudios sobre la retórica, primero, a partir de nuevas propuestas teóricas sobre la argumentación y la retórica, a raíz de la publicación en 1964 del Tratado de la argumentación de Chaïm Perelman y Lucie Olbrechts-Tyteca (1979) y la de Los usos de la argumentación de Stephen Toulmin, en el 2003. Segundo, gracias a nuevos estudios sobre la Retórica de Aristóteles, entre los que cabe mencionar el de Edward Meredith Cope (1970), An Introduction to Aristotle's Rhetoric, el de William M. A. Grimaldi (1972), Studies in the Philosophy of Aristotle's Rhetoric, y los ensayos recopilados en Aristotle's Rhetoric por D. J Furley y A. Nehamas (1994). Sobre los estudios de retórica, Carlo Natali (2002) hace una completa presentación en "Aristóteles y el renacimiento de la retórica". También en América Latina hubo nuevos estudios sobre el tema, como es el caso de la Retórica, inducción y ciencia en Aristóteles: Epistemología de la epagogé, de Héctor Zagal Arreguín (1993), y de las Teorías aristotélicas del discurso, de Luis Xavier López-Farjeat (2002). 
Por su parte, los estudios sobre el método en la Política se han orientado a mostrar los diversos caminos que sigue Aristóteles en su investigación. Keyt (1987), por ejemplo, considera que Aristóteles concebía la polis como un artefacto; Pellegrin (2011) sostiene que el método de indagación del Estagirita es equiparable al que utiliza en sus tratados biológicos. A su vez, Elisabetta Poddighe (2017) muestra la importancia que para Aristóteles tiene el conocimiento histórico en la construcción de su teoría política: con este se amplía el juicio, pues permite recoger datos históricos con los que se obtienen visiones de conjunto sin las que no sería posible la ciencia política.

En el marco de las anteriores indagaciones, a continuación me ocupo de la teoría de la esclavitud de Aristóteles en el libro I de la Política con el fin de mostrar la utilización de dos tipos de procedimientos: uno dialéctico y otro retórico. Estableceré que Aristóteles procede dialécticamente cuando discute con Sócrates, Platón y los sofistas, y retóricamente al recurrir al testimonio. Sostendré que esta distinción entre procedimientos dialécticos y retóricos implica, a su vez, la que Aristóteles hace entre las opiniones admisibles (endoxa), la tesis (hypólepsis parádoxos) y el testimonio (martyría) y, específicamente, entre los endoxa y la martyría, dado que ambos se refieren a lo que es admitido, lo que puede dar lugar a que estos no sean claramente diferenciados ni ubicados en sus correspondientes procedimientos. A partir de lo anterior, me concentro en el testimonio para mostrar el papel que este tiene en la elaboración de su teoría sobre la esclavitud y sus consecuencias epistemológicas.

\section{Procedimiento dialéctico y retórico}

En los Tópicos, Aristóteles acude a las opiniones admisibles (endoxa) y a la tesis (hypólepsis parádoxos) para describir el método dialéctico. Por su parte, en la Retórica, dedicada al estudio de la persuasión retórica, en los libros I y II se ocupa del testimonio (martyría). La fuerza persuasiva de endoxa, hypólepsis parádoxos y martyría radica en la reputación que se les atribuye. Las opiniones admisibles (endoxa) son proposiciones que derivan su admisibilidad de todos, de la mayoría o de los más reputados: "Son cosas plausibles las que parecen bien a todos, o a la mayoría, o a los sabios, y, entre estos 
últimos, a todos, o a la mayoría, o a los más conocidos o reputados" (Tóp., 100b 21-24). A su vez, la tesis (hypólepsis parádoxos) deriva su valor epistemológico de la posición sustentada por un filósofo en virtud de su elaboración teórica, y se diferencia de lo que hasta ahora ha sido admitido: "una tesis es un juicio paradójico de alguien conocido, en el terreno de la filosofía” (Tóp., 104b 19-20). En cuanto al testimonio (martyría), es considerado en el libro I de la Retórica entre las pruebas sin arte (esto es, no construidas discursivamente), y en el libro II se indica como prueba discursiva utilizada por los oradores y con la misma fuerza persuasiva de los ejemplos.

Si admitimos la anterior distinción sobre las funciones que endoxa, hypólepsis parádoxos y martyría cumplen en ámbitos distintos, se puede entonces proceder a identificar en el libro i de la Política los dos tipos de procedimientos: dialéctico y retórico, y el papel que allí cumplen.

\section{La teoría de la esclavitud}

La elaboración de una teoría de la esclavitud por parte de Aristóteles en el libro I de la Política responde a su necesidad para la vida en la polis o comunidad. Aristóteles afirma que la polis es la comunidad más perfecta y la más digna de alcanzarse. Para demostrarlo, recurre a dos perspectivas de análisis: con la primera establece el tipo de autoridad que hace posible su realización; en la segunda muestra la evolución que conduce a la constitución de la Polis. En el primer análisis recurre a la dialéctica, pues parte de opiniones reputadas (endoxa) ${ }^{4}$ para, a partir de su examen, proponer su propia tesis (hypólepsis parádoxos): "No tienen razón, por tanto, los que creen que es lo mismo ser gobernante de una ciudad, rey, administrador de su casa o amo de sus esclavos" (Pol., I, 1, 1252a 6-8). A continuación, Aristóteles recurre a dos tipos de argumentos, el primero especifica que la polis es una comunidad, una unidad compuesta por elementos entre los que se dan distintas relaciones:

4 Estas corresponden, según Tricot en la nota 3 de su edición al francés, a Sócrates (Xénoph., Mem., III, 4, 12) y a Platón (Pol., I, 258e-259d; Aristóteles, 1962, p. 22). 
Pero esto no es verdad, como resultará claro considerando la cuestión según el método que nosotros seguimos; porque de la misma manera que en las demás ciencias es menester dividir lo compuesto hasta llegar a sus simples, pues éstos son las últimas partes del todo, así también considerando de qué elementos consta la ciudad veremos mejor en qué difieren unas de otras las cosas dichas, y si es posible obtener algún resultado científico sobre cada una de ellas (Pol., I, 1, 1252a 16-23).

Por su parte, el segundo argumento distingue entre dos tipos de autoridad: una de mando y obediencia; la otra de gobernante y gobernados. Las relaciones de autoridad que se dan entre ellos se determinan de acuerdo con el fin para el cual son establecidas: las de macho-hembra y padre-hijos para la procreación; la del amo-esclavo para la manutención y, finalmente, la de gobernantes-gobernados para el bien de la ciudad. Todas estas relaciones, a su vez, se ordenan hacia la consecución del fin último: el bien de la ciudad.

En esta segunda perspectiva del análisis Aristóteles muestra la evolución que conduce a la constitución de la Polis, desde de las comunidades más simples -casa, aldeas, etnos ${ }^{5}$ hasta llegar a la más compleja: la polis. Nos dice que la casa aparece para suplir las necesidades básicas de procreación y manutención; luego, se unen varias casas en aldeas y etnos para garantizar mejor su preservación y, finalmente, se llega a la constitución de la polis, con la que, además de la procreación y la manutención, se busca la realización de la vida mejor. Cada comunidad no desaparece con el surgimiento de las posteriores, sino que se van incorporando una a la otra con el fin de constituir la última comunidad. Así, la última se conforma por dos partes: la casa y la polis. Con la casa (oikos) se satisfacen las necesidades de procreación y de manutención. Y con la polis se busca la realización del bien último. Aristóteles concluye que se requieren, entonces, dos formas de autoridad: la despótica, la ejercida por el padre-amo sobre su esposa, los hijos y sus esclavos, y la del gobierno que se da entre -y para- los ciudadanos.

Por consiguiente, según Aristóteles, esta comunidad perfecta es una unidad en la que se requieren dos tipos de autoridad: una

5 Este término alude, según Tricot, a una comunidad menor que la polis, pues no posee constitución propia (Aristóteles, 1962, n. 7, p. 26). 
para garantizar la preservación de la casa; la otra para alcanzar el fin último. Ahora sí podemos detenernos entonces en la identificación de los dos procedimientos, dialéctico y retórico, que Aristóteles utiliza cuando construye su teoría de la esclavitud. El Estagirita procede dialécticamente al examinar las opiniones reputadas (endoxa) que, hasta entonces, habían sido sostenidas por los filósofos anteriores sobre la esclavitud, con el fin de proponer su propia tesis (hypólepsis parádoxos). Estas opiniones son, según Tricot (1962), las de Platón, Sócrates y la de los sofistas ${ }^{6}$ sobre si la esclavitud es justa o injusta:

Unos opinan, en efecto, que el señorío es una ciencia y que el gobierno de la casa, el del amo, el de la ciudad y el del rey son una misma cosa, como dijimos al principio; otros, que la dominación es contraria a la naturaleza, ya que el esclavo y el libre lo son por convención y en nada difieren naturalmente; y por ello tampoco es justa, puesto que es violenta (Pol., I, 3, 1253b 18-22).

Al examinar dichas opiniones y proponer su propia tesis, Aristóteles acude a dos tipos de argumentos: el primero parte de la observación de distintas formas de "unidad"7 en las que las partes le están subordinadas, pues solo así se garantiza que se alcance su fin. Una de estas unidades se da en las cosas inanimadas, en las que las partes se subordinan a la unidad para lograr la armonía; otra unidad acontece en las animadas, en las que hay un principio rector: el alma que mantiene la vida como tal. La subordinación de las partes a la

6 Según Tricot, traductor al francés de la Política: "Aristote fait allusion à certain Sophistes

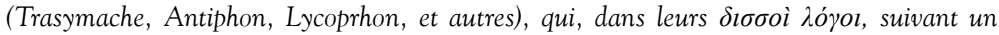
mécanisme décrit de Soph. elench., 12, 173 a 7-16, démontrait leurs thèses outrancières en s'appuyant sur l'antique opposition de la convention (ou de la loi, vónos) et de la nature

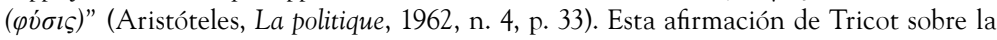
alusión que hace Aristóteles a los sofistas Trasímaco, Antifonte, Lycofrón y otros puede verificarse con el reconocido estudio sobre los sofistas de Mario Untersteiner I sofisti.

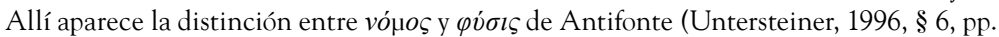
369-377) y las de Trasímaco, Lycofrón y otros (1996, § 2-7, pp. 497-517).

7 El término al que acude Aristóteles en este pasaje y traducido por "unidad" es $\delta \ddot{\lambda} o \varsigma$. En la Metafísica, en el libro v, Aristóteles se ocupa en precisarlo. Allí, Valentín García Yebra lo traduce al español, en su acepción general, por "entero" y lo diferencia, a la vez, del término $\pi \alpha \nu \tau o ́ \varsigma$ que prefiere traducir por "todo": "Entero se llama algo a lo que no le falta ninguna parte de aquellas por las cuales se llama entero por naturaleza, y lo que contiene las cosas contenidas de manera que éstas sean algo uno; y esto puede ser de dos maneras: pues o bien son uno individualmente, o bien se compone de ellos la unidad [...]. Además, teniendo la cantidad principio, medio y fin, de aquellas cosas en que la posición no establece diferencia se dice 'todo', y de aquellas en que la establece, 'entero'” (Met., V, 26, 1023b 26 y 1024a 3). 
unidad es necesaria, conveniente y, por lo tanto, justa, pues cada parte debe contribuir a su realización. Aristóteles al verificar mediante la observación qué tipo de "unidad" es la polis, afirma que es semejante a la de las cosas animadas y establece, por extensión, que en la casa ese principio rector y justo es el padre-amo y, por lo tanto, las demás partes deben subordinarse a él. Esta forma de argumentar corresponde a la que describe Aristóteles en los Tópicos como comprobación o inducción, que también hace parte de la dialéctica:

Una comprobación, en cambio, es el camino desde las cosas singulares hasta lo universal; v. g.: si el más eficaz piloto es el versado en su oficio, así como el cochero, también en general el versado es el mejor en cada cosa. La comprobación es un argumento más convincente y claro, más accesible a la sensación y común a la mayoría, mientras que el razonamiento es más fuerte y más efectivo frente a los contradictores (Tóp., I, 12, 105a 10-15).

El segundo argumento que utiliza Aristóteles para examinar la opinión de los sofistas es distinguir los diferentes significados de un término, procedimiento que, al igual que el anterior, es contemplado en los Tópicos (cfr. Tóp., I, 15, 106a 1-37):

porque las palabras esclavitud y esclavo tienen dos sentidos: hay también, en efecto, esclavitud y esclavos en virtud de una ley, y esta ley es una convención según la cual lo cogido en la guerra es de los vencedores. Muchos entendidos en leyes denuncian, sin embargo, este derecho como denunciarían por ilegalidad a un orador; para ellos es cosa tremenda que el que pueda ejercer la violencia y es superior en fuerza haga de su víctima su esclavo y vasallo (Pol., I, 6, 1255a 4-11).

Al examinar los distintos significados de esclavitud, Aristóteles considera que hay algo de verdad en cada uno: unos al reconocer la autoridad que se da entre amos y esclavos, los otros al considerar que la violencia no puede legitimar la esclavitud. Sin embargo, para Aristóteles ambos se equivocan al establecer el principio, pues la esclavitud debe examinarse desde lo que es justo para la unidad que es la comunidad política. ${ }^{8}$ En este caso, los hombres que no poseen la capacidad para gobernar deben estar subordinados a la unidad, pues solo así contribuyen al bien último: vivir bien.

8 Este principio va en contravía de la igualdad entre los hombres, que corresponde al derecho natural, defendido, como vemos por los sofistas y asumido, siglos más tarde, por Francisco de Vitoria, a quien se considera fundador del Derecho Internacional Moderno (cf. Sánchez, 2004). 
A continuación, Aristóteles no solo recurre a este tipo de procedimientos dialécticos, sino que, con el fin de darle mayor solidez a su tesis, recurre a otros dos tipos de procedimientos que son retóricos: la metáfora y el testimonio. Dejamos de lado el análisis de la metáfora ${ }^{9}$ utilizada por Aristóteles en la elaboración de su teoría de la esclavitud, pues nuestro propósito es, más bien, detenernos en el testimonio. La razón de esta elección, como ya lo habíamos advertido, es que el testimonio, al igual que las opiniones admisibles y la tesis, derivan su fuerza persuasiva de la reputación de quienes los emiten y por esta razón es preciso señalar que tienen un papel distinto en la argumentación.

\section{El testimonio}

En la Retórica, Aristóteles se refiere a los testigos y al testimonio en los libros I, 2 y 15 y en el II, 20. En el primero, los testigos, junto a los documentos y las confesiones, son incluidos en las pruebas sin arte (’̈ $\tau \varepsilon \chi v o i ́)$ (Ret., I, 2, 1355b, 35-39). En el segundo, al estudiar el discurso forense, distingue entre dos clases de testigos ( $\mu \alpha \dot{\alpha} \rho \tau v \rho \varepsilon ́ \varsigma)$ : los antiguos $(\pi \alpha \lambda \alpha \imath o i)$ y los recientes $(\pi \rho o ́ \sigma \varphi \alpha \tau o l)$ y precisa que a ellos se acude debido a la calidad de su juicio:

Acerca de los testigos: Los testigos son de dos clases, unos antiguos ( $\pi \alpha \lambda \alpha ı o v ̀ \varsigma)$, otros recientes, y de estos últimos, los unos participan del riesgo del acusado, los otros están fuera. Llamo antiguos a los poetas y a todos los famosos cuyos juicios son conocidos; así los atenienses se sirvieron de

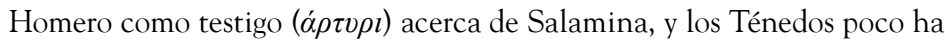
de Periandro de Corinto contra los de Sigeo y Cleofonte contra Cristias se sirvió de las elegías de Solón, diciendo que de antiguo la familia carecía de vergüenza, porque si no, no hubiera Solón escrito:

"Dile a Critias el pelirrojo que escuche a su padre" (Ret., I, 15, 1375b 29-34).

[...] Son testigos recientes cuantas personas conocidas han opinado algo,

9 Aristóteles define en la Poética la metáfora y sus distintas especies (cf. Pol., I, 1475b 7-33) y a ella se remite en la Retórica para precisar su fuerza persuasiva (cf. Ret., III, 2, 5, 1405a 3-1407 a 17). Para completar su teoría de la esclavitud, Aristóteles utiliza algunas de las que él denomina especies de metáforas: la comparación (cf. Ret., III, 4, 1406b 19-23), los proverbios (Ret., III, 11, 1413a 16-19) y la ironía (Ret., III, 19, 1419b, 35 1420a 2). 
pues sus juicios son útiles para los que disputan sobre las mismas cosas; así Ebulo en los tribunales se sirvió contra Cares de lo que Platón había dicho contra Arquibio, de que se extendía en la ciudad confesar que se es malo (Ret., I, 15, 1376a 8-12).

Aristóteles considera que los testimonios, al ser emitidos por quienes tienen una determinada reputación, en este caso los poetas o los famosos, tienen valor persuasivo. ${ }^{10}$ Edward Meredith Cope, en An Introduction to Aristotle's Rhetoric (1970), se refiere a la diferencia que Aristóteles establece entre los testimonios de los antiguos y los nuevos, entre antiguos, modernos y contemporáneos. Los testigos antiguos son los poetas, cuyos versos se convierten en evidencia autorizada del pasado y, también, los adivinos y profetas que con sus proverbios ofrecen un soporte para el futuro. Los famosos -los contemporáneos- son los que actualmente tienen una reputación y son los que acuden a los estrados judiciales a dar su testimonio. Los antiguos tienen un alto grado de credibilidad, pues han recibido la sanción del tiempo; mientras que los nuevos tienen menos credibilidad, pues pueden ser objeto de corrupción.

Aristóteles en el libro II incluye los testimonios entre las pruebas discursivas, al decir que los ejemplos obtienen valor persuasivo cuando operan como los testimonios:

Es preciso, cuando no se dispone de entimemas, servirse de ejemplos como demostración (porque en ellos se funda la persuasión), y teniendo entimemas hay que servirse de ejemplos como de testimonios ( $\mu \alpha \rho \tau v \rho i ́ o r \varsigma)$, poniendo los entimemas como de remate, pues poniéndolos delante se asemejan a la inducción, y en la oratoria no es propia la inducción, excepto en pocos casos; dichos en el remate se asemejan a los testimonios ( $\mu \alpha \rho \tau v \rho i ́ o r \varsigma)$ y el testigo ( $\mu \alpha \dot{\rho} \rho \tau \varsigma)$ en todos los casos es digno de fe. Por eso el que los pone al principio, por fuerza tiene que decir varios; y en el epílogo uno solo puede bastar, porque un testigo bueno, él solo basta (Ret., II, 20, 1394a 9-16).

10 La reputación deviene en autoridad y como tal tiene valor persuasivo. Este recurso a la autoridad, como lo afirma Christopher W. Tindale (2015) en The Philosophy of Argument and Audience Reception, fue desvalorizada por la ilustración; pero que como lo reconoce Gadamer, sí tienen su propio valor cognoscitivo: "la autoridad de las personas no tiene su fundamento último en un acto de sumisión y de abdicación de la razón, sino en un acto de reconocimiento y de conocimiento: se reconoce que el otro está por encima de uno en juicio y perspectiva y que en consecuencia su juicio es preferente o tiene primacía respecto al propio" (Gadamer, 1977, p. 347). 
Los ejemplos que tienen el valor de un testimonio son, según Aristóteles, tomados de la historia o de lo que ha sucedido; pero también son inventados:

De ejemplos ( $\pi \alpha \rho \alpha \delta \varepsilon \gamma \gamma \mu \alpha \dot{\tau} \omega v)$ hay dos especies: la una es decir cosas que han sucedido antes, la otra inventarlas. De esta especie una cosa es parábola ( $\pi \alpha \rho \alpha \beta o \lambda \eta ̀)$, otra fábulas ( $\lambda$ ó $\gamma o 1)$ como las esópicas y las líbicas (Ret., II, 20, 1393a 27-31).

Así, vemos que Aristóteles en la Retórica no solo reconoce el valor testimonial que tiene la historia, sino también la literatura y, por ende, le adjudica fuerza persuasiva.

Pero el valor persuasivo que le adjudica Aristóteles al testimonio no es de uso exclusivo de la retórica; en la Ética Eudemia nos dice que a este se recurre cuando se examina el buen vivir y cómo se adquiere, asunto que le compete a la ciencia política:

Pero, en lo que respecta a todas estas cuestiones, debemos intentar buscar el convencimiento por medio de argumentos, usando los hechos manifiestos como testimonio ( $\mu \alpha \rho \tau v \rho i o l \varsigma)$ y ejemplos. Pues lo mejor sería que todos los hombres se mostraran de acuerdo con lo que se va a decir, y, si no, al menos que todos se muestren de acuerdo de algún modo, lo que harán si se les cambia poco a poco [para ello]; pues cada uno tiene algo propio en relación con la verdad, de lo cual es necesario partir para demostrar de algún modo estas cuestiones, porque a partir de afirmaciones verdaderas, aunque no claras, si se avanza, se harán también claras, siempre que se adopten las más conocidas en lugar de las habituales que se dicen confusamente (EE., I, 6, 1216b 26-37).

Joseph Karbowski (2016), en "Phainomenas Witnesses and Examples: The Methodology of Eudemia Ethics 1.6", analiza este pasaje con el propósito de establecer que, a diferencia de lo que han mostrado otros comentaristas, Aristóteles en la Ética no solo recurre al método de los endoxa, sino a los ejemplos y testimonios que, según lo afirma este autor, proceden de lo empírico. ${ }^{11} \mathrm{~A}$ diferencia de lo anterior, nuestra posición es que acudir a los testimonios tiene una

11 Karbowski opta por diferenciar los endoxa de lo empírico; sin embargo, dicha distinción no está exenta de dificultades, como se puede evidenciar por las discusiones que se dieron a propósito de los términos endoxa y phainómena, sobre los que no existe un acuerdo sobre el sentido que Aristóteles les adjudicó. Cfr. Le Blond (1939), Owens (1980 [1961]), Nussbaum (1995) y Berti (2009). 
función retórica. A continuación, lo comprobaremos con el uso que Aristóteles hace del testimonio en la configuración de su teoría sobre la esclavitud en la Política.

Para esclarecer el papel de los testimonios en la elaboración de la teoría de la esclavitud consideramos necesario esbozar antes la diferencia que establece Aristóteles entre ciudadano y esclavo. A diferencia de la mujer y de los niños, el esclavo no es un hombre libre, pues le pertenece al amo, es su propiedad. La mujer y los hijos, aún siendo libres, no son ciudadanos. Para ser ciudadano se requiere ser hombre y libre. Muy brevemente traemos unas citas extraídas de los libros I y III de la Política que condensan bien sus pensamientos. En el libro I de la Política afirma del esclavo que

De aquí se deduce claramente cuál es la naturaleza y la facultad del esclavo: el que por naturaleza no pertenece a sí mismo, sino a otro, siendo hombre, ése es naturalmente esclavo; es hombre de otro el que, siendo hombre, es una posesión, y la posesión es un instrumento activo e independiente (Pol., I, 4, 1254a 13-17).

En el libro III, refiere del ciudadano:

El ciudadano sin más por nada se define mejor que por participar en la administración de justicia y en el gobierno (Pol., III, 1, 1275a 22-23).

De lo anterior se deriva que el esclavo es quien, aun siendo un hombre, le pertenece a otro y desarrolla las capacidades dadas por naturaleza, que le son necesarias para cumplir eficazmente con las tareas que le son asignadas en la casa. El hombre libre desarrolla la capacidad de deliberación, que también tiene la mujer, y además, la de mando, pues estas le son necesarias para tomar decisiones sobre lo que es justo, conveniente y mejor para la ciudad: ${ }^{12}$

El libre rige al esclavo de otro modo que el varón a la hembra y el hombre al niño, y en todos ellos existen las partes del alma, pero existen de distinto modo: el esclavo carece en absoluto de facultad deliberativa; la hembra la tiene, pero desprovista de autoridad; el niño la tiene, pero imperfecta (Pol., I, 13, 1260a 9-14).

12 Esta precisión sobre las capacidades que le corresponden al esclavo y al ciudadano ha sido puesta de presente y discutida sobre cómo interpretar la afirmación que hace Aristóteles en esa dirección. Cfr. Russell (1999), Goodey (1999), Frank (2004), Heath (2008), y Vlassopoulos (2011). 
Esbozada la distinción entre esclavo y ciudadano indicaremos a seguir el papel que le adjudica Aristóteles al testimonio en el libro i de la Política. Allí recurre al testimonio cuando examina la opinión de quienes "consideran justa la esclavitud que resulta de la guerra, pero al mismo tiempo la niegan” (Pol., I, 6, 1255a 23-24). Esta afirmación la sustenta con un testimonio que extrae de la Ilíada:

\begin{abstract}
Algunos, ateniéndose en su opinión a la justicia (puesto que la ley es una cosa justa), consideran justa la esclavitud que resulta de la guerra, pero al mismo tiempo la niegan: pues la causa de la guerra puede no ser justa, y no se puede llamar de ninguna manera esclavo a quien no merece la esclavitud; de otro modo se dará el caso de que los que parecen mejor nacidos sean esclavos e hijos de esclavos si son hechos prisioneros y vendidos. Por eso los griegos no quieren llamarse a sí mismos esclavos, sino a los bárbaros, y cuando dicen esto no pretenden hablar de otra cosa que del esclavo por naturaleza, como dijimos desde el principio; en efecto, es forzoso reconocer que unos son esclavos en todas partes y otros no lo son en ninguna. Y lo mismo con la nobleza: los griegos se consideran a sí mismos nobles no solo entre ellos, sino en todas partes, pero a los bárbaros sólo en su país, juzgando que hay una nobleza y libertad absoluta $(\dot{\alpha} \pi \lambda \tilde{\omega} \varsigma$ $\varepsilon \dot{\gamma} \gamma \varepsilon v \dot{\varepsilon} \varsigma$ $\kappa \alpha i ̀ ~ c ́ \lambda \varepsilon v ́(\varepsilon \rho o v)$ ), y otra no absoluta, como afirma la Helena de Teodecto: Fruto de dos raíces divinas, ¿quién se atrevería a llamarme sierva? ("Ocíwv $\delta$ "

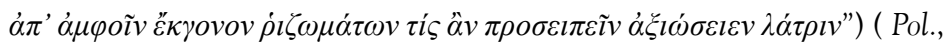
I, 6, 1255a 21-38).
\end{abstract}

El valor que tiene este testimonio es innegable, pues procede de la Ilíada, que se constituye en el referente por excelencia para la educación de los griegos. Con ella los griegos se forjaron una imagen de sí mismos, a partir de las ideas de nobleza y de libertad. Con esta imagen los griegos asumieron que eran superiores a los que no lo eran y así justificaron el suficiente mérito para gobernar la ciudad y legitimaban con ello subordinar a los que no eran como ellos. Solo ellos por sus características podían asignarles tareas a los demás: niños, mujeres, esclavos. Sin embargo, Aristóteles afirma que si bien la naturaleza tiende a establecer las diferencias entre esclavos y libres, no siempre lo logra y, por esto, se debe recurrir a las capacidades que cada uno tiene para servir, deliberar o mandar: "en algunos hombres su condición de esclavos o libres está bien definida, y entonces es conveniente para el uno ser esclavo y para el otro dominar, y es justo, y uno debe ser regido y otro regir según su disposición natural y, por tanto, también dominar" (Pol., I, 6, 1255b 6-9). 
Encontramos también que Aristóteles recurre a otro testimonio, esta vez extraído de la historia, para reforzar su afirmación sobre la diferencia entre el amo y el esclavo en cuanto al tipo de conocimiento que requieren, pues cada uno debe asumir tareas distintas:

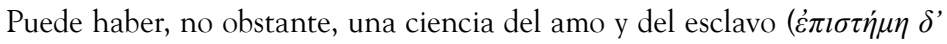

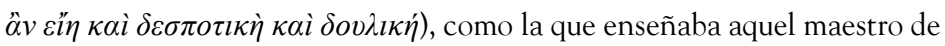
Siracusa que, mediante un sueldo, instruía a los esclavos en sus menesteres ordinarios (Pol., I, 7, 1255b, 22-25).

Comprobamos así que Aristóteles recurre a los testimonios cuando elabora su teoría de la esclavitud para darle mayor valor de verdad a sus afirmaciones, pues estos al extraerse tanto de la literatura como de la historia son admisibles y gozan de una determinada reputación. Tal como lo plantea en la Ética Eudemia, Aristóteles considera válido recurrir a los testimonios cuando se examina el buen vivir y, en este caso, para elaborar su teoría de la esclavitud, que considera justa de mantener por el bien de la polis. Pero es en la Retórica donde encontramos las precisiones sobre el papel que tienen los testimonios y su función persuasiva. Son estas las que nos permiten, al identificar el uso que hace Aristóteles en la Política del testimonio, esclarecer su papel metodológico y precisar su función retórica, pues lo que observamos es que añaden valor persuasivo a las demostraciones dialécticas emprendidas por Aristóteles sobre la esclavitud.

\section{Endoxa, hypólepsis parádoxos y martyría}

Este recorrido por la teoría de la esclavitud de Aristóteles nos permite establecer, en primer lugar, que, para elaborar su teoría de la esclavitud, Aristóteles utiliza dos tipos de procedimientos: uno dialéctico y otro retórico. En segundo lugar, que endoxa y hypólepsis parádoxos pertenecen a la dialéctica, y martyría a la retórica. En tercer lugar, que endoxa, hypólepsis parádoxos y martyría tienen en común la misma característica: ser reputados. En cuarto lugar, que se diferencian por el papel que se les asigna en la dialéctica y en la retórica a cada uno. En quinto lugar, que Aristóteles utiliza procedimientos dialécticos y retóricos en la construcción de su teoría de la esclavitud: los procedimientos dialécticos para establecer las opiniones reputadas (endoxa) sobre el tema objeto de indagación, 
examinarlas y sustentar la tesis (hypólepsis parádoxos) con nuevos argumentos; los procedimientos retóricos, entre los que se cuenta el uso del testimonio (martyría), para darle mayor fuerza persuasiva a sus demostraciones $\mathbf{I}$

\section{Referencias}

Aubenque, P. (1984). El problema del ser en Aristóteles (V. Peña, Trad.). Taurus.

Aristóteles. (1962). La Politique (J. Tricot, Trad.). Vrin.

Aristóteles. (1982). Tópicos. En Tratados de lógica (Órganon) (pp. 89-306), (M. Candel Sanmartín, Trad.). Gredos.

Aristóteles. (1987). Metafísica (V. García Yebra, Trad.). Gredos.

Aristóteles. (1990). Retórica (A. Tovar, Trad.), 4.ㄹ ed. Centro de Estudios Constitucionales.

Aristóteles. (2002). Ética Eudemia (C. Megino Rodríguez, Trad.). Alianza.

Aristóteles. (2005). Política. (J. Marías y M. Araújo, Trads.). Centro de Estudios Políticos y Constitucionales.

Berti, E. (2001-2002). Il valore epistemologico degli endoxa secondo Aristotele. Seminarios de Filosofía, (14-15), 111-128. https://bit. ly/32ljLYE

Berti, E. (2009). 'Phainomena' ed 'endoxa' in Aristotele. En W. Lapini, L. Malusa, \& G. Brigati (Eds.), Gli antichi e noi. Scritti in onore di Antonio Mario Battegazzore (pp. 107-119). G. Brigati.

Cope, E. M. (1970). An Introduction to Aristotle's Rhetoric with Analysis Notes and Appendices. Georg Olms Verlag.

Frank, J. (2004). Citizens, Slaves, and Foreigners: Aristotle on Human Nature. The American Political Science Review, 98(1), 91-104. https:// bit.ly/2PlfCi0

Furley, D. J. \& Nehamas, A. (1994). Aristotle's Rhetoric: Philosophical Essays. Proceedings of the 12th Symposium Aristotelicum. Princeton University Press. 
Gadamer , H.-G. (1977). Verdad y Método. Fundamentos de una hermenéutica filosófica. Sígueme.

Goodey, C. (1999). Politics, Nature and Necessity. Were Aristotle's Slaves Feeble Minded? Political Theory, 27(2), 203-224. https:/doi. org/10.1177/0090591799027002003

Grimaldi, W. (1972). Studies in the Philosophy of Aristotle's Rhetoric. Franz Steiner Verlang GMBH.

Heath, M. (2008). Aristotle on Natural Slavery. Phronesis, 53(3), 243-270. https://doi.org/10.2307/1087451

Karbowski, Joseph. (2016). Phainomenas Witnesses and Examples: The Methodology of Eudemia Ethics 1.6. Oxford Studies in Ancient Philosophy, 49, 193-226. https://bit.ly/2SSsZbO

Keyt, D. (1987). Three Fundamental Theorems in Aristotle's Politics. Phronesis, 32(1), 54-79. https://bit.ly/38QItBJ

Le Blond, J. L. (1939). Logique et méthode chez Aristote: étude sur la recherche des principes dans la physique Aristotélicienne. Librairie Philosophique J. Vrin.

López-Farjeat, L. X. (2002). Teorías aristotélicas del discurso. Universidad de Navarra.

Marcos, A. (1996). Aristóteles y otros animales: Una lectura filosófica de la biología. Promociones y Publicaciones.

Martino, E. (1975). Aristóteles, el alma y la comparación. Gredos.

Natali, C. (2002). Aristóteles y el renacimiento de la retórica. Logo: Revista de Retórica y Teoría de la Comunicación, 2(2), 85-100. https://bit. ly/2IPdrQ4

Nussbaum, M. (1995). La fragilidad del bien. Fortuna y ética en la tragedia y la filosofía griega. Visor.

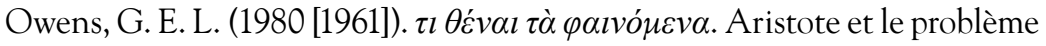
de méthode. En Communications présentées au Symposium Aristotelicum tenu à Lovain (pp. 613-616). Institut Supérieur de Philosophie.

Pellegrin, P. (2011). Parties de la cité, parties de la constitution. En C. Natali (Ed.), Aristotle Metaphysics and Practical Philosophy. Essays in Honour of Enrico Berti (pp. 177-200). Peeters Publishers. 
Perelman, C., y Olbrechts-Tyteca, L. (1979). Tratado de la argumentación. La nueva retórica. Gredos.

Poddighe, E. (2017). La funzione della conoscenza storica nella teoria politica e nella teoria precettistica retorica secondo Aristotele: l'importanza della visione globale. NOVA TELLVS, 35(2), 61-81. https:// doi.org/10.19130/iifl.nt.2017.35.2.768

Russell, B. (1999). Loving Freedmon: Aristotle on Slavery and Good Life Political Studies. Political Studies, 47(1), 100-113. https://doi. org/10.1111/1467-9248.00190

Sánchez, A. M. (2004). "Todas las gentes del mundo son hombres”: el gran debate entre Fray Bartolomé de las Casas (1474-1566) y Juan Ginés de Sepúlveda (1490-1573). Anales de Historia de la Filosofía, (21), 91-134. https://bit.ly/2vbywRI

Symposium Aristotelicum. (1980). Aristote et les problèmes de méthode: Comunications Présentées au Symposium Aristotelicum tenu à Lovain du 24 août au septembre 1960, 2. ${ }^{a}$ ed. Institut Supérieur de Philosophie.

Toulmin, S. (2007). Los usos de la argumentación. Península.

Untersteiner, M. (1996). I sofisti. Bruno Mondadori.

Tindale, W. (2015). The Philosophy of Argument and Audience Reception. Cambridge University Press.

Vlassopoulos, K. (2011). Greek Slavery: From Domination to Property and Back Again. The Journal of Hellenis Studies, 131, 115-130. https://bit. ly/38VKyNI

Zagal, A. H. (1993). Retórica, inducción y ciencia en Aristóteles: Epistemología de la epagogé. Universidad Panamericana. 